\title{
Drug Treatment Among Mandated Female Drug Abusers in a Faith-Based Program: Religion/Spirituality as a Predictor of Motivation in Treatment
}

\author{
Robert D. Hanser \\ University of Louisiana at Monroe, Louisiana, USA
}

\begin{abstract}
The purpose of this study was to determine if female drug abusers in a faith-based drug treatment program would have higher levels of motivation in treatment based on their self-reported religious and/or spiritual orientation. This study utilized the religiosity/spirituality subscale and the sexual abuse subscale from the PEI-A (Personal Experience Inventory-Adult) and a variety of mental health related subscales from the MAQ (Maryland Addiction Questionnaire). Results of the study found significant relationships between religious orientation and motivation in treatment programming.
\end{abstract}

Keywords: substance abuse, drug abuse, religion, spirituality, women and drugs

\section{Introduction}

Within the field of correctional treatment, there has been an emerging interest in the study of female offenders. This increased interest began in the late 1990s when it was observed that the incarceration of women was increasing at a greater rate than that of men (Kruttschnitt \& Gartner, 2006). Though women represented only a small segment of the correctional population, especially in the institutional segment, they were, nonetheless, increasing at a faster rate than ever. The reason for this was largely attributed to the war on drugs which, with the more vigorous modes of enforcement and enhanced prison penalties, resulted in an increased rate of female offenders behind bars and on community supervision (Mauer, Potler, \& Wolf, 2006).

The increased number of women convicted of drug crimes usually stemmed from their drug use rather than drug trafficking (Mauer et al., 2006). As a result, there was a growth in the number and type of drug treatment programs offered to female drug offenders. The study and evaluation of programs designed for female offenders came into vogue during the late 1990s extending into the new millennium. From 2000s onward, it was clear that the correctional treatment literature had become inclusive of the female offender population; and it was also clear that treatment programming for this population should be, at least to some extent, gender-specific to the needs of women.

A variety of programs around the nation were developed to specifically address drug issues for women (Bloom, Owen, \& Covington, 2003; Bradey \& Ashley, 2005). Among these types of programs were those that emphasized cognitive approaches, those that emphasized affective issues, those with gender-specific groups, and those with mixed gender groups, as well as those with other modes of intervention. Thus, programs were

Robert D. Hanser, associate professor, associate director, School of Social Sciences, University of Louisiana at Monroe. 
grounded in both theoretical orientations as well as gender-based or structural processes.

\section{Substance Abuse and Female Drug Offenders}

Substance abuse is a major contributor to female criminality. Substance abuse is correlated with a number of female crimes, such as prostitution and shoplifting. Often these other crimes are committed to support the female offenders' drug problem. Further, female offenders tend to use alcohol, cocaine, and heroine as drugs of choice. These are highly addictive drugs that require intensive treatment. Indeed, women are particularly in need of quality drug abuse interventions since female offenders are more likely than male offenders to use drugs, they use more serious drugs than male offenders, and they use them more frequently. Further, female offenders are more likely than men to be under the influence of drugs at the time of their crimes (Kassebaum, 1999).

Results of a study by Henriques (2002) showed that there are a myriad of factors to consider with most female offenders in treatment. For example, some of these women come pregnant or in a post-partum state, whereas others may have dependent children who are placed in the custody of relatives or foster homes. Amidst this, most gynecological services in criminal justice treatment programs are inadequate in addressing reproductive issues that range from drug-related high-risk pregnancies, sexually transmitted diseases, to poor prenatal nutrition (Henriques, 2002).

Therefore, female offenders are likely to be in more need of drug treatment that must be designed to be gender-specific. Indeed, all female rather than co-educational settings are more supportive and comfortable environments for speaking about such issues as domestic violence, sexual abuse and incest, shame, and self-esteem. Recently, women's treatment experts have been calling for new treatment models designed specifically for women. Adding special services to a male treatment model should not be considered sufficient. Rather, the female treatment program must be separate from the traditional male treatment models to ensure that it fits the psychological and social needs of women (Kassebaum, 1999).

\section{Faith-Based Paradigms of Drug Abuse Treatment}

During the Bush administration, there came support for a treatment paradigm that had typically not been highlighted in most of the professional literature on drug treatment, which is faith-based programs (De Vita \& Wilson, 2001). These programs have received attention in various professional conferences (Crawford, 2003) and with various government agencies (Office of Applied Studies, 2006). While faith-based treatment programs have proliferated throughout the US (United States) during the past decade, there is limited research on the actual effectiveness of these programs in drug abuse treatment. Indeed, De Jong and Horn (2008) made implication of the challenges involved in this research through the very title of their presentation, Opening of the Black Box of Faith-based Services: Measuring Program Components and Treatment Dose, that was published by the US Department of Health and Human Services at the 2008 Conference on Faith-Based and Community Initiatives Conference on Research, Outcomes, and Evaluation. The reason for showcasing their research is to simply demonstrate that even as late as 2008, this body of research was still considered under-developed.

To be sure, there have been researches on religion and spirituality in the drug treatment literature (Crawford, 2003; Ebaugh, Chafetz, \& Pipes, 2006; Ellis \& Schoenfeld, 1990; Hugen, DeJong, \& Venema, 2005; Hugh, Elifson, \& Sterk, 2006; Johnson, 2002; Longshore, Anglin, \& Conner, 2008; Neff \& MacMaster, 2005). In some instances, these researchers have found that spiritual and/or religious variables do significantly impact 
various aspects of drug treatment outcomes (Pardini, Plante, Sherman, \& Stump, 2000; Neff, Shorkey, \& Windsor, 2009). There are also some existing researches that have examined mental health benefits of faith-based approaches in drug treatment programs (Pardini et al., 2000). However, these studies were fairly limited in existence and few, if any, specifically examine the effectiveness of faith-based drug treatment approaches with female drug offenders. Finding this type of specific research is difficult, and just as important, there exists a dearth of this type of research that examines outcomes on motivation. Most current research does not determine whether the individual has effectively overcome the drug using lifestyle and thought patterns but simply indicates whether they have been able to refrain from drug using behavior.

\section{Women and Religiosity}

There is an abundance of research that supports the notion that women tend to be more religious than men, at least as demonstrated by self-reported research (Miller \& Stark, 2002; Walter \& Davie, 1998; Thompson, 1991). In fact, within the literature on religious research in a variety of academic disciplines, this is a generally accepted notion (Miller \& Hoffman, 1995; Walter \& Davie, 1998; Thompson, 1991). Further, Kanazawa (2010) pointed to a worldwide survey that included over 100,000 people from 70 nations around the world where it was found that women self-reported to be more religious than men. These findings were true for women regardless of the region of the world and regardless of the particular religion (Kanazawa, 2010). This phenomenon is not really profound or new in research on this related topic. However, finding the reasons why this observation is true has been the subject of extensive study and some degree of debate.

There have been some researches that have found that gender differences in religious affiliation are correlated with differences in risk preferences (Miller \& Hoffman, 1995). According to these researchers, religious behavior is risk averse, whereas non-religious behavior has a greater propensity to be risky. Because women are proposed to be less prone toward risky behavior, they are thought to be more likely to report higher levels of religious involvement and belief. Other researchers, such as Miller and Stark (2002) also found that women are more religious than their male counterparts and their level of religiosity is inversely related to their willingness to engage in risk-taking behaviors. This finding is significant, because drug abuse is considered as a risky behavior and, if by implication of the research by Miller and Stark, women in drug treatment with high levels of religiosity should fare better in drug treatment. The route of logic is as follows: The more religious the participant, the less likely they would be to engage in risky behaviors. This is then followed with the idea that these participants will be more responsive to treatment and presumably, this would result in better outcomes.

Research by Stark (2002) concluded that the connection between religion and women is similar to that between men and crime. Since men seem to be more prone to risky behaviors, particularly criminal behaviors, they will tend to be less religious in affiliation and in their level of commitment. On the other hand, because women tend to engage in fewer risky behaviors and since these behaviors, when they occur, tend to be less serious, they will be more likely to indicate religious affiliation and they will tend to be more religious in orientation (Stark, 2002). Even more to the point of this thesis, research by Hugh, Elifson, and Sterk (2006) examined correlations between religiosity and drug use among at-risk female participants. They (Hugh et al., 2006) found that religiosity is indeed related to the amount of drugs that women used; the more religious that they are, the lower the drug use.

Research by Richard, Bell, and Carlson (2000) examined the religiosity and church attendance of participants in drug and alcohol treatment. While they found that increases in church attendance are 
significantly associated with reductions in cocaine use, they did not find support for self-reported religious commitment and drug treatment effectiveness. Other research by Windsor and Shorkey (2010) found that participants who stayed in treatment for longer periods of time had significantly higher levels of spirituality. While this research, on the face of it, seems encouraging, it is actually a bit misleading, because this does not at all demonstrate that religion or spirituality has anything to do with the treatment outcome of these participants. Rather, it is the case that if participants decided to stay in treatment for longer periods of time, they began to acquire more religious attitudes. Thus, this means that the program evaluated by these researchers is successful at encouraging religion among participants, not that religion encourages participants to be more successful in the program (Windsor \& Shorkey, 2010).

On the other hand, Longshore et al. (2008) noted correlations between drug abuse treatment and religiosity and spirituality. These researchers (Longshore et al., 2008) indicated that while studies result in correlations, most of these studies have substantial flaws in the methodologies that are used, instruments that are selected, or the sample that is examined. They (Longshore et al., 2008) specifically pointed toward the difficulties in measuring religion and spirituality as a construct. In addition, there is a lack of research that examines the impact of religiosity/spirituality on mental health indicators that co-occur with drug abuse (Miller \& Warner, 2009).

Lastly, Neff et al. (2009) examined the challenges involved with researching faith-based substance abuse treatment programs. In addition, these researchers examined seven treatment programs, four of which were faith-based and three of which were traditional programs to identify specific themes and approaches to each type of program. They found no differences in group activities and cohesion. These researchers also found that both types of orientations included similar core social processes, such as mentoring, role modeling, and an emphasis on social cohesion (Neff et al., 2009).

From the previous researches, it can be seen that there is support in the literature for the idea that women identify with religion more than men. Further, this observation has been correlated with a likelihood toward risk aversion; the more religious a person, the less likely they are to engage in risky behaviors. Further, this has also been extended to drug abusing behavior where specific support exists for the notion that as women become more religious the lower their drug use will tend to be. However, there is few research that uses standardized quantitative measures of drug treatment effectiveness within faith-based programs and among those that do, there is little or no support that religion or spirituality actually, unto itself, has a significant correlation with effective drug treatment outcomes. Further, it would appear that these programs, when compared with traditional programs, are more similar than different.

\section{Women and Faith-Based Treatment}

It would seem that faith-based treatment programming has the capacity to mesh well with other gender-specific aspects of drug treatment for female drug abusers (Neff et al., 2009; CSAT-Center for Substance Abuse Treatment, 2009). While not necessarily a panacea in the pursuit of recovery from drugs and alcohol, it may well be that this modality is as effective or perhaps even more effective in meeting the needs of female drug offenders (Kendler, Liu, Gardner, Mc-Cullough, Larson, \& Prescott, 2003). In fact, the use of religion and spirituality in drug treatment has been specifically cited as a feature of a strength-based approach to drug treatment with women (CSAT, 2009).

Faith-based programs, being religious in nature, tend to emphasize family connections including both 
adult-adult relationships as well as those associated with the woman and her children. Researches have shown that the prognosis for women in drug treatment is enhanced when they have contact with their children, significant others, or extended family members (CSAT, 2009). While it is true that traditional drug treatment programs can and do also emphasize relationships among female drug abusers, it may well be that the spiritual element of faith-based approaches can further enhance these connections, particularly among women who desire this type of modality.

One other benefit to faith-based approaches is that they tend to provide a philosophical overlay or theme in the treatment modality. This existential nature of these approaches can add meaning to life challenges that otherwise may have little or no rational explanation. This is especially true with medical illnesses, accidents, and injuries (Koenig, 2004). Because, as we have seen, women are often prior victims of physical abuse, sexual abuse, domestic violence, and other sources of trauma, a religious and/or spiritual approach may aid these offenders in coping with these traumas since they can provide some type of spiritual explanation for tragic and traumatic events, pain, and suffering that they have faced in their lives (Kendler, Gardner, \& Prescott, 1997; Kendler et al., 2003).

\section{Hypothesis}

From the literature provided, it should be clear that there are sufficient grounds for inquiry as to whether religion and/or spirituality will be predictive of drug treatment outcomes in a faith-based program. While this makes intuitive sense, there is a dearth of quantitative research that clearly and specifically links the connection between spiritual/religious orientation and drug treatment effectiveness. Because researches show that women tend to be more religious than men and because the inclusion of religious and/or spiritual elements have been likened to a gender-appropriate approach to drug treatment with women, it is of particular interest to see if religiosity and spirituality are linked to drug treatment outcomes among female drug abusers. Therefore, based on the literature review and the comments just provided, the hypothesis for this study is as follows:

Ho: As participants score higher on the spirituality/religiosity subscale, their scores on motivation subscales will significantly improve.

\section{Methodology}

\section{Overview}

This study consisted of a post-test only, quasi-experimental, and within-subjects design. Participants were female drug abusers who attended treatment in a faith-based residential treatment facility. The author completed a face-to-face structured interview with each of the participants of this study at intake and upon completion of the 90-day period of treatment (commonly referred to as Phase I at the facility). During intake, the author administered the PEI-A (Personal Experience Inventory-Adult) (Winters, 1995) to participants after completing the structured interview with each participant. Upon completion of the 90-day treatment program, the author conducted another follow-up structured interview, and upon completion of that interview, administered the MAQ (Maryland Addiction Questionnaire) (O’Donnell, C. B. DeSoto, \& J. L. DeSoto, 1997a) to each participant prior to their entry into Phase II, which was a second 90-day period of treatment for women who continued treatment.

\section{Participants}

Participants in this study were female drug abusers in a local faith-based residential drug treatment 
program for women $(n=48)$. There were three cases that were not included in this sample of 48 participants due to their inability to complete the 90 -day treatment program. These cases were discarded among the sample since their data were unusable, because no outcome measures were obtained. The age range of participants was from 19 to 50, with a mean age of 32.7 years old.

\section{Materials}

The PEI-A is a self-reported inventory that provides comprehensive information about substance abuse patterns in adults aged 19 or older (Winters, 1995). This instrument can be used to identify drug and alcohol problems and to aid in treatment planning. Further, because substance abuse problems rarely occur in isolation, this instrument also assesses a wide array of other psychosocial problems that tend to be associated with substance abuse. The PEI-A was written at a sixth-grade reading level and has two parts: the Problem Severity Section (consisting of 120 items) and the Psychosocial Section.

The Problem Severity Scale has 120 items that make up 22 subscales that examine factors related to the times, places, and social conditions of drug use as well as specific types of drugs that have been used by participants (Winters, 1995). Importantly, though the data were collected among these clients, it should be noted that data from these subscales were not used in the current study. The Psychosocial Section has 150 items that make up another 22 subscales that examine factors, such as negative self-image, deviant behavior, suicide risk, and a variety of other characteristics that are associated with drug use (Winters, 1995). It is from the Psychosocial Severity Scale (Winters, 1995) that items from the spiritual/religiosity subscale and the physical/sexual abuse victim subscale were obtained.

The spiritual/religiosity subscale consists of seven items that include a 4-Likert scale form of ordinal forced response. For the first six items, four choices are available, as follows: "Strongly disagree”, "Disagree”, "Agree", and "Strongly agree". The seventh item also provides four choices that are as follows: "Seldom or never”, "Sometimes”, “Often”, and “Almost always”.

The MAQ is designed to be used with participants aged 17 and older and is written at the fifth-grade level (O'Donnell et al., 1997b). Norms for this instrument are based on a large sample of participants who received drug abuse treatment in outpatient settings, residential facilities, and halfway house programs. This means that this instrument was normed on a population that was very similar to that within the current study, at least from the perspective of involvement in treatment. This self-reported instrument consists of 111 items that examine the severity of a respondent's addiction, their level of motivation in treatment, as well as a handful of co-occurring mental health disorders.

\section{Research Design}

This study was a within-subject, posttest-only, and quasi experimental design (Hagan, 2005; Martin, 2008). The reason for this classification is that the same participants are used in two different pre-treatment and post-treatment measures. However, this is not a true pre-test/post-test design, because each measure at each point uses a different data collection instrument. The PEI-A (Winters, 1995) was used at intake and the MAQ (O’Donnell et al., 1997a) was used when participants completed the 90-day of treatment. Thus, it was concluded that, since the outcome measures used were only taken at the end of the treatment program, the study should be classified as a post-test design that is only within-subjects (Martin, 2008).

In addition, this study does not have a control group nor does it have a comparison group, making it a quasi experimental design (Hagan, 2005; Martin, 2008). Initially, it was thought that a control or comparison 
group might be included in this study, but upon careful examination of the other potential female-specific programs available, none was similar enough in characteristics to make a valid comparison. Indeed, other potential control/comparison groups either consisted of mixed-gender (male and female) groups or female-specific groups with females who were out-patient clients (not residential) or were in a jail facility receiving other addiction intervention services.

\section{Procedure}

The author was identified as the evaluator for the agency in which this study was conducted. The author conducted several structured interviews with each participant, both during intake and other points in their treatment regimen to obtain additional data on each participant. This helped to allow the author to establish a rapport with participants that went beyond the mere administration of the testing instruments. Further, data collection consisted of the administration of the PEI-A (Winters, 1995) when clients reported to the treatment facility at intake.

Once, participants either neared completion of their 90 days of treatment, or shortly thereafter, the author administered the MAQ (O’Donnell et al., 1997a; 1997b) to these participants. The author, prior to administering the MAQ, conducted a follow-up interview and also provided a debriefing process for participants involved in the research project. All required guidelines were followed to maintain compliance with the Public Health Service Act, now titled Title 42, Section 290dd-3, of the United States Code. This law is also known as Title 42, part 2, of the Code of Federal Regulations.

\section{Statistical Analyses}

Statistical analyses for hypothesis testing in this study included linear regression and a multiple ANOVA (analysis of variance). Each of these statistical analyses was selected, because they were the most appropriate option for the data that were utilized, and they were capable of producing results that answered the specific hypothesis that was tested. Linear regression was used to test the hypothesis of this study. Lastly, ANOVA was used to compare economic status group mean outcomes on motivation indicators from the MAQ. While these forms of analyses are basic in nature, they were selected because they are generally accepted methods of analysis in the fields of psychology and criminal justice, and because, as previously stated, they were suitable analyses for answering the specific research hypotheses presented in this study.

\section{Results}

\section{Descriptive Statistical Analyses}

The first demographic variable examined was the racial identity of the participants. Racial orientation among the participants included 87.5\% Caucasian women and 12.5\% African American women. The racial composition of this sample of drug offenders in treatment did not reflect the racial demographics of the surrounding population, and therefore, was probably not generalizable to the region from which it was drawn.

The data on income were obtained from other sources of data collection that were also administered by the author. Participants in this study largely came from low income backgrounds with more than half reporting $\$ 200$ to $\$ 300$ per week (about $\$ 800$ to $\$ 1,200$ monthly). Approximately 92\% reported weekly incomes of $\$ 600$ or less per week (roughly $\$ 2,400$ a month, or less). It is clear that women in this program make a lower middle class income or even less. This is fairly reflective of the majority of the drug offending population who are mandated through this region's drug court and is reflective of much of the drug offending population who are 
not mandated but present for treatment at this facility and other facilities similar to the one in this study.

This analysis was conducted using a simple linear regression to determine if scores on the spiritual/religiosity subscale were significant predictors of motivation outcomes in drug treatment within a faith-based program. Data in Table 1 indicate that the dependent variable, MOT (motivation in treatment), is significant. Thus, religiosity/spirituality significantly predicted MOT scores, $B=0.553, t_{(46)}=8.041, p<0.05$. However, the effect size is small with an $R^{2}$ of only 0.142 , and while being significant, does not account for a substantial proportion of the observed variance in this predictive model. Despite this, it is clear that, at least to some small effect, religion/spirituality does play a role in motivation among these participants in drug treatment.

Table 1

Regression Analysis for Motivation Regressed on Religion/Spirituality

\begin{tabular}{llllll}
\hline Variable & $N$ & $B$ & $S E B$ & $\beta$ & Sig. \\
\hline Motivation in treatment (MOT) & 48 & 0.553 & 0.201 & 0.376 & $0.008^{*}$ \\
\hline Note. $^{*} p<0.05$. & & & &
\end{tabular}

\section{Discussion}

From the prior analysis, it is clear that the findings of this study show that there was a relationship between religiosity/spirituality and motivation. Though this may seem like a fairly basic finding, this is, in fact, an important finding. This is particularly true given the emphasis on motivational interviewing techniques within substance abuse treatment programs. Indeed, Carroll et al. (2006) found that integrating motivational interviewing techniques in the earliest phases of treatment may have positive effects on retention early in the course of treatment. This is important, because this study was focused on outcomes from early stages of treatment. Further, the author utilized motivational interviewing techniques as did much of the staff at the treatment facility. Generally speaking, literature demonstrates that as clients are more motivated, they are also likely to experience longevity in treatment and this translates to even better outcomes.

Thus, it can be speculated that the significant relationship between motivation and spiritual/religious beliefs provides a good fit for participants who are serious-minded about recovery. Likewise, it may be that the program's appeal to spiritual aspects of a participant's identity helps to solidify a rapport and to cement the participant to the recovery regimen. While all of these are somewhat speculative, there is consistent research that validates these points. Part of the reason for this continued commitment to the treatment program from one phase to the next may be linked to the connected nature of religion and motivation in this treatment program.

Aside from this, it is important to note that there are several limitations that have impacted this study. Before providing discussion on these limitations, this study examined a very unique area of substance abuse treatment that is in need of exploration. Often, studies that examine unique areas of research will encounter challenges that make it all but inevitable that flaws in a design and/or analysis will emerge. It is the contention of this researcher that exploration and research of under-examined areas within a given body of knowledge should be encouraged. With this said, it is nonetheless necessary to at least mention some of the limitations that were encountered.

\section{Limitations}

First, there was neither a control group nor a comparison group in this study. This means, of course, that 
the rigor associated with a true experimental design was not obtained in this study. Further, though this study is classified as a quasi experimental design, this particular study did not include any pre-test and post-test measures using similar items or scales for comparison. To be clear, the data were collected by the author as part of the more comprehensive evaluation process of the treatment program.

Second, the sample size is small and it is possible that the statistical power- the probability that a model will yield a significant result if the hypotheses are true - has been negatively affected. However, A. Aron, E. N. Aron, and Coups (2008) noted that mechanisms to increase effect size can offset deficiencies in statistical power within a study. Some examples that exist would be to reduce variance by using a less diverse population, using more reliable measures, or increasing the intensity of the experimental treatment. In reality, all three of these strategies were employed. The sample was very homogenous in nature (including race, income, and other demographic features); the measures were taken from instruments that have been validated and found to be reliable; and the experimental treatment was quite intensive, as observed by the author and as articulated by many participants during structured interviews with the author. Thus, it is unclear as to the extent that deficits in statistical power may have impacted the results of this study.

Third, the sample in this study was overwhelmingly Caucasian (87.5\%). Future studies would be well served to include more diversity within the sample, including Latino American and Asian American representation for this claim to be solid. Indeed, the issues related to the racial composition of the sample are, in actuality, likely to be important for another key reason. The African American community tends to emphasize religion and/or spirituality (D. W. Smart \& J. F. Smart, 1997). Researches on other racial groups have also found similar results, further lending credibility to the notion that racial diversity in similar studies should be considered a priority.

\section{Conclusions}

This study demonstrates that for female substance abusers, the use of religion and/or spirituality in treatment programming may be effective in developing gender-appropriate programming. In addition, this study helps to point the way toward additional research that may better investigate the potential for faith-based approaches to augment clinical interventions related to substance abuse as well as co-occurring disorders. Though faith-based approaches may not be appropriate for all clinical issues and for all participants who report for substance abuse treatment, it is a treatment option that some clients may prefer and this may create an environment in which they are more comfortable. Perhaps, it is the sense of comfort that is the healing mechanism to the challenges that these clients face. This may also explain the high levels of program completers and the persistence that were observed among most of the participants within the program.

\section{References}

American Psychiatric Association. (2000). Diagnostic and statistical manual of mental disorders-Text revision. Arlington, V. A.: American Psychiatric Association.

Aron, A., Aron, E. N., \& Coups, E. J. (2008). Statistics for the behavioral and social sciences (4th ed.). Upper Saddle River, N. J.: Pearson Prentice Hall.

Bloom, B., Owen, B., \& Covington, S. (2003). Gender-responsive strategies: Research, practice, and guiding principles for women offenders. Washington, D. C.: National Institute of Corrections. Retrieved June 8, 2007, from http://www.nicic. org/pubs/2003/018017.pdf

Bradey, T. M., \& Ashley, O. S. (2005). Women in substance abuse treatment: Results from the alcohol and drug services study. Washington, D. C.: Substance Abuse and Mental Health Services Administration. 
Brome, D. R., Owens, M. D., Allen, K., \& Veveaina, T. (2000). An examination of spirituality among African American women in recovery from substance abuse. Journal of Black Psychology, 26(4), 471-486.

Carroll, K. M., Ball, S. A., ... Woody, G. E. ( 2006). Motivational interviewing to improve treatment engagement and outcome in individuals seeking treatment for substance abuse: A multisite effectiveness study. Drug \& Alcohol Dependence, 81(3), 301-312.

Comfort, M., \& Kaltenbach, K. A. (2000). Predictors of treatment outcomes for substance-abusing women: A retrospective study. Substance Abuse, 21(1), 33-45.

Crawford, D. L. (2003). Federally funded faith-based substance abuse treatment services for African American substance abusers at risk for HIV demonstrate significant reduction in substance use. Presented at the National HIV Prevention Conference, Atlanta, Georgia, 2003.

CSAT (Center for Substance Abuse Treatment). (2009). Substance abuse treatment: Addressing the specific needs of women (TIP 51). Rockville, M. D.: Substance Abuse and Mental Health Services Administration.

De Jong, F. J., \& Horn, C. (2008). Opening of the black box of faith-based services: Measuring program components and treatment dose. Compendium of Research Papers Presented at the Faith-Based and Community Initiatives Conference on Research, Outcomes, and Evaluation (pp. 147-177). Retrieved from http://aspe.hhs.gov/fbci/comp08/

De Vita, C. J., \& Wilson, S. (2001). Faith-based initiatives: Sacred deeds and secular dollars. Washington, D. C.: The Urban Institute.

Ebaugh, H. R., Chafetz, J. S., \& Pipes, P. F. (2006). Where's the faith in faith-based organizations? Measures and correlates of religiosity in faith-based social service coalitions. Social Forces, 84(4), 2259-2272.

Ellis, A., \& Schoenfeld, E. (1990). Divine intervention and the treatment of chemical dependency. Journal of Substance Abuse, 2, 459-468.

Gravetter, F. J., \& Wallnau, L. B. (2004). Statistics for the behavioral sciences (6th ed.). Belmont, C. A.: Wadsworth.

Hagan, F. E. (2005). Research methods in criminal justice and criminology (7th ed.). Allyn \& Bacon.

Henriques, Z. (2002). Diversion programming: Integrating treatment with criminal justice sanctions for women with co-occurring disorders. In S. Davidson, \& H. Hills (Eds.), Series on women with mental illness and co-occurring disorders. Delmar, N. Y.: National GAINS Center.

Hugen, B., DeJong, F., \& Venema, R. (2005). Faith makes a difference: A study of faith in human service programs. Acton Institute: Policy Form, Summer(6), 1-12.

Hugh, K., Elifson, K. W., \& Sterk, C. E. (2006). The relationship between religiosity and drug use among "at risk” women. Journal of Religion and Health, 45(1), 45-56.

Hurst, G. A., Williams, M. G., King, J. E., \& Vicken, R. (2008). Faith-based intervention in depression, anxiety, and other mental disturbances. Southern Medical Journal, 101(4), 388-392.

Johnson, B. R. (2002). Objective hope assessing the effectiveness of faith based organizations: A review of the literature. Philadelphia: University of Pennsylvania, Center for Research on Religion and Urban Civil Society.

Kanazawa, S. (2010, Sept.). Why are women more religious than men? Psychology Today. Retrieved from http://www.psychologytoday.com/.../why-are-women-more-religious-men-i

Kassebaum, P. A. (1999). Substance abuse treatment for women offenders: Guide to promising practices (DHHS Publication No. (SMA) 99-3303). Rockville, M. D.: US Department of Health and Human Services.

Kendler, K. S., Gardner, C. O., \& Prescott, C. A. (1997). Religion, psychopathology, and substance use and abuse; A multimeasure, genetic-epidemiologic study. American Journal of Psychiatry, 154(3), 322-329.

Kendler, K. S., Liu, X. Q., Gardner, C. O., Mc-Cullough, M. E., Larson, D., \& Prescott, C. A. (2003). Dimensions of religiosity and their relationship to lifetime psychiatric and substance use disorders. American Journal of Psychiatry, 160(3), 496-503.

Koenig, H. (2004). Religion, spirituality, and medicine: Research findings and implications for clinical practice. Southern Medical Journal, 97(12), 1194-1200.

Kruttschnitt, C., \& Gartner, R. (2006). Penal policies and women inmates in the 1990s. In R. Immarigeon (Ed.), Women and girls in the criminal justice system: Policy issues and practice strategies (pp. 31-36). Kingston, N. J.: Civic Research Institute, Inc..

Lewis, L. M. (2004). Culturally appropriate substance abuse treatment for parenting African American women. Issues in Mental Health Nursing, 25(5), 451-472.

Longshore, D., Anglin, M. D., \& Conner, B. T. (2008). Are religiosity and spirituality useful constructs in drug treatment research? Journal of Behavioral Health and Services \& Research, 36(2), 177-188. 
Martin, D. W. (2008). Doing psychology experiments (7th ed.). Belmont, C. A.: Wadsworth.

Mauer, M., Potler, C., \& Wolf, R. (2006). The impact of the drug war on women: A comparative analysis in three states. In R. Immarigeon (Ed.), Women and girls in the criminal justice system: Policy issues and practice strategies (pp. 61-69). Kingston, N. J.: Civic Research Institute, Inc..

Miller, A. S., \& Hoffman, J. P. (1995). Risk and religion: An explanation of gender differences in religiosity. Journal for the Scientific Study of Religion, 34(1), 63-75.

Miller, A. S., \& Stark, R. (2002). Gender and religiousness: Can socialization explanations be saved? American Journal of Sociology, 107(6), 1399-1423.

Miller, L., \& Warner, P. (2009). Religiosity and depression: Ten-year follow-up of depressed mothers and offspring. Journal of the American Academy of Child \& Adolescent Psychiatry, 36(10), 1416-1425.

Neff, J. A., \& MacMaster, S. A. (2005). Spiritual mechanisms underlying substance abuse behavior change in faith-based substance abuse treatment. Journal of Social Work Practice in Addictions, 5(3), 33-54.

Neff, J. A., Shorkey, C., \& Windsor, L. C. (2009). Using concept mapping to identify program dimensions of faith-based substance abuse treatment programs. New Brunswick, N. J.: Rutgers University Press.

Nelson-Zlupko, L., Dore, M. M., Kauffman, E., \& Kaltenbach, K. (1996). Women in recovery: Their perceptions of treatment effectiveness. Journal of Substance Abuse Treatment, 13(1), 51-59.

O’Donnell, W. E., DeSoto, C. B., \& DeSoto, J. L. (1997a). Maryland addiction questionnaire. Los Angeles, C. A.: Western Psychological Services.

O’Donnell, W. E., DeSoto, C. B., \& DeSoto, J. L. (1997b). Maryland addiction questionnaire: Manual. Los Angeles, C. A.: Western Psychological Services.

Office of Applied Studies. (2006). Facilities offering special programs or groups for women: 2005. Retrieved March 11, 2008, from http://www.oas.samhsa.gov/2k6/womenTx/womenTX.htm

Pardini D. A., Plante T. G., Sherman A., \& Stump J. E. (2000). Religious faith and spirituality in substance abuse recovery: Determining the mental health benefits. Journal of Substance Abuse Treatment, 19(4), 347-54.

Richard, A. J., Bell, D. C., \& Carlson, J. W. (2000). Individual religiosity, moral community, and drug user treatment. Journal for the Scientific Study of Religion, 39(2), 240-246.

Riehman, K. S., Hser, Y. I., \& Zeller, M. (2000). Gender differences in how intimate partners influence drug treatment motivation. Journal of Drug Issues, 30, 823-838.

Smart, D. W., \& Smart, J. F. (1997). DSM-IV and culturally sensitive diagnosis: Some observations for counselors. Journal of Counseling and Development, 75, 392-397.

Stark, R. (2002). Physiology and faith: Addressing the "universal” gender difference in religious commitment. Journal for the Scientific Study of Religion, 41, 495-507.

Substance Abuse and Mental Health Services Administration. (1999). Enhancing motivation for change in substance abuse treatment (TIP 35). Rockville, M. D.: Substance Abuse and Mental Health Services Administration.

Thompson, E. H. (1991). Beneath the status characteristics: Gender variations in religiousness. Journal for the Scientific Study of Religion, 30(4), 381-394.

Walter, T., \& Davie, G. (1998). The religiosity of women in the modern west. The British Journal of Sociology, 49(4), 640-660.

Windsor, L. C., \& Shorkey, C. (2010). Spiritual change in drug treatment: Utility of the Christian inventory of spirituality. Substance Abuse, 31(3), 136-145.

Winters, K. C. (1995). Personal experience inventory for adults. Los Angeles, C. A.: Western Psychological Services. 